\title{
Heart block in patients with obstructive sleep apnoea: pathogenetic factors and effects of treatment
}

\author{
U. Koehler*, E. Fus*, W. Grimm**, W. Pankow*, H. Schäfer+, A. Stammnitz*, J.H. Peter*
}

Heart block in patients with obstructive sleep apnoea: pathogenetic factors and effects of treatment. U. Koehler, E. Fus, W. Grimm, W. Pankow, H. Schäfer, A. Stammnitz, J.H. Peter. C)ERS Journals Ltd 1998.

ABSTRACT: Heart block during sleep has been described in up to $10 \%$ of patients with obstructive sleep apnoea. The aim of this study was to determine the relationship between sleep stage, oxygen desaturation and apnoea-associated bradyarrhythmias as well as the effect of nasal continuous positive airway pressure (nCPAP)/nasal bilevel positive airway pressure (nBiPAP) therapy on these arrhythmias in patients without electrophysiological abnormalities.

Sixteen patients $(14$ males and two females, mean age $49.6 \pm 10.4 \mathrm{yrs})$ with sleep apnoea and nocturnal heart block underwent polysomnography after exclusion of electrophysiological abnormalities of the sinus node function and atrioventricular (AV) conduction system by invasive electrophysiological evaluation.

During sleep, 651 episodes of heart block were recorded, 572 (87.9\%) occurred during rapid eye movement (REM) sleep and $79(12.1 \%)$ during nonrapid eye movement (NREM) sleep stages 1 and 2. During REM sleep, the frequency of heart block was significantly higher than during NREM sleep: $0.69 \pm 0.99$ versus $0.02 \pm 0.04$ episodes of heart block $\cdot \mathrm{min}^{-1}$ of the respective sleep stage $(\mathrm{p}<0.001)$. During apnoeas or hypopnoeas, 609 bradyarrhythmias $(93.5 \%)$ occurred with a desaturation of at least $4 \%$. With nCPAP/ nBiPAP therapy, apnoea/hypopnoea index (AHI) decreased from $75.5 \pm 39.6 \cdot h^{-1}$ to $3.0 \pm$ $6.6 \cdot h^{-1}(p<0.01)$ and the number of arrhythmias from 651 to $72(p<0.01)$.

We conclude that: 1) $87.9 \%$ of apnoea-associated bradyarrhythmias occur during rapid eye movement sleep; 2) the vast majority of heart block episodes occur during a desaturation of at least $4 \%$ without a previously described threshold value of $72 \%$; and 3) nasal continuous positive airway pressure or nasal bi-level positive airway pressure is the therapy of choice in patients with apnoea-associated bradyarrhythmias.

Eur Respir J 1998; 11: 434-439.
Heart block during sleep is found in $5-10 \%$ of patients with obstructive sleep apnoea [1-4]. Apnoea-associated bradyarrhythmias often exceed $2 \mathrm{~s}$ in duration, and asystolies of up to $15.6 \mathrm{~s}$ in duration have been observed [2, 5, $6]$. We have previously described electrophysiological findings in patients with apnoea-associated bradyarrhythmias suggesting that poorly understood, vagally mediated reflex mechanisms rather than structural abnormalities of the sinus node and the atrioventricular (AV) conduction system cause these bradyarrhythmias $[7,8]$. In addition, BECKER et al. [5] from this group previously demonstrated that heart block in patients with obstructive sleep apnoea can be abolished in the majority of patients by nasal continuous positive airway pressure. A desaturation to less than $72 \%$ has been identified to be a precondition for the occurrence of heart block [2]. Guileminault et al. [2] reported apnoea-associated bradyarrhythmias only during nonrapid eye movement (NREM) sleep stage II and rapid eye move-

In response to these observations, this study was designed to clarify the relationship between sleep stage, arterial oxygen saturation $\left(\mathrm{Sa}_{\mathrm{a}} \mathrm{O}_{2}\right)$ and apnoea-associated bradyarrhythmias in patients with normal electrophysiological evaluation. ment (REM) sleep [2].
Depts of *Internal Medicine and **Cardiology, Schlafmedizinisches Labor, PhilippsUniversity Marburg, Germany. +Dept of Internal Medicine, University of Bonn, Germany.

\section{Correspondence: U. Koehler}

Medizinische Poliklinik

Baldingerstrasse 1

35033 Marburg

Germany

Fax: 496421284958

Keywords: Atrioventricular block electrophysiological evaluation nasal continuous positive airway pressure obstructive sleep apnoea rapid eye movement sleep sinus arrest

\section{Received: December 161996} Accepted after revision October 291997
Philipps-University Marburg

\section{Patient selection}

The study population was recruited from patients referred to our out-patient department because of suspected sleep apnoea. Sixteen patients fulfilled the following inclusion criteria for our study: 1) obstructive sleep apnoea (apnoea/hypopnoea index (AHI) $>10 \cdot \mathrm{h}^{-1}$ and associated nocturnal bradyarrhythmias as documented by ambulatory monitoring of breathing sounds, cardiac frequency $(f \mathrm{C}), \mathrm{Sa}_{\mathrm{a}} \mathrm{O}_{2}$, and body position (MESAM IV; Madaus Schwarzer; Munich, Germany) and a two-channel Holter electrocardiogram (ECG) (Oxford Medilog 4000; Oxford Instruments, Abingdon, UK); and 2) unremarkable electrophysiological ev-aluation of sinus node and AV conduction function as described in detail below. In all patients a diagnostic cardiorespiratory polysomnography was performed. nCPAP/ nasal bi-level positive airway pressure (nBiPAP) therapy was introduced the day after polysomnography. The study was approved by the institutional Ethics Review Board of the University of Marburg. Written informed consent was obtained from all patients 
Clinical characteristics of 16 study patients

Mean age of the patients was $49.6 \pm 10.4$ yrs (range $27-72 \mathrm{yrs}$ ). Average height was $174.6 \pm 7 \mathrm{~cm}$ (range 163$186 \mathrm{~cm}$ ) and weight $111.4 \pm 20.3 \mathrm{~kg}$ (range $81-150 \mathrm{~kg}$ ). Body mass index (BMI) was $36.8 \pm 7.9 \mathrm{~kg} \cdot \mathrm{m}^{-2}$ (range $28.1-$ $\left.54.2 \mathrm{~kg} \cdot \mathrm{m}^{-2}\right)$. Arterial hypertension was found in 13 patients $(81.3 \%)$, hyperlipidaemia and hyperuricaemia in nine $(56.3 \%)$ and diabetes in two patients $(12.5 \%)$. None of the patients had a history of myocardial infarction.

Pulmonary function test, blood gas analysis, echocardiography, clinical/chemical examinations, as well as 12 lead ECG at rest and during exercise were performed. All patients underwent a maximal graded bicycle stress test in supine position. A minimum load of $50 \mathrm{~W}$ was performed, which was increased by $25 \mathrm{~W}$ every $2 \mathrm{~min}$. Twelve-lead ECGs were printed out for each minute during exercise and for the first $5 \mathrm{~min}$ of recovery. An ischaemic ECG response was defined as $>1 \mathrm{~mm}$ horizontal or downsloping ST segment depression for $>0.08 \mathrm{~s}$ after the $\mathrm{J}$ point on at least three consecutive beats. There was no evidence of coronary heart disease in any of the 16 patients as determined by bicycle stress test, ECG at rest and history. None of the patients complained about symptoms of angina pectoris.

The presence of left ventricular hypertrophy was defined as a left ventricular (LV) mass index to body surface area of more than $125 \mathrm{~g} \cdot \mathrm{m}^{-2}$. LV mass was calculated according to an anatomically validated formula [9]:

$$
\text { LV mass }=1.04 \cdot\left[(\text { IVS+PWT+LVID })^{3}-(\text { LVID })^{3}\right]-13.6
$$

where IVS is the interventricular septal thickness, PWT is the posterior wall thickness and LVID is the left ventricular internal dimension. In 11 out of the 16 study patients, echocardiography revealed signs of left ventricular hypertrophy.

Chronic obstructive airway disease (forced expiratory volume in one second (FEV1)/vital capacity (VC) <60\%) was found in seven patients, nine patients did not show any pathology in lung function. Blood gas analysis produced a mean arterial oxygen tension $\left(\mathrm{Pa}_{\mathrm{a}} \mathrm{O}_{2}\right)$ of $9.3 \pm 0.9$ $\mathrm{kPa}(69.8 \pm 6.9 \mathrm{mmHg}$ ) (range 7.6-11.2 kPa (56.9-84.0 $\mathrm{mmHg})$ ), a mean arterial carbon dioxide tension $\left(\mathrm{Pa}_{\mathrm{a}}, \mathrm{CO}_{2}\right)$ of $5.5 \pm 0.4 \mathrm{kPa}(41.1 \pm 3.3 \mathrm{mmHg}$ ) (range $4.6-6.2 \mathrm{kPa}(34.4-$ $46.5 \mathrm{mmHg}$ )), and a mean $\mathrm{Sa}, \mathrm{O}_{2}$ of $93.1 \%$ (range 88.595.4).

\section{Diagnosis of sleep apnoea and bradyarrhythmias}

In the out-patient department, in addition to the clinical interview and physical examination, a visually analysed ambulatory monitoring of breathing sounds, $f \mathrm{C}, \mathrm{Sa}_{\mathrm{a}} \mathrm{O}_{2}$, and body position (MESAM IV; Madaus Schwarzer) from approximately 18:00-08:00 $\mathrm{h}$ and a two-channel Holter ECG (Oxford Medilog 4,000) from approximately 14:00-08:00 $\mathrm{h}$ were performed. All patients with $\mathrm{III}^{\circ} \mathrm{AV}$ conduction block, $\mathrm{II}^{\circ} \mathrm{AV}$ conduction block type Mobitz II and sinus arrest of at least $2 \mathrm{~s}$ in duration were included in the study. No patient received digoxin, $\beta$-blockers, verapamil or class I or III anti-arrhythmic medication during polysomnography or before the study.
Definitions of normal electrophysiological evaluation of sinus node and AV conduction function

Electrophysiological evaluation of sinus node function and AV conduction properties before and after administration of atropine $\left(0.02 \mathrm{mg} \cdot \mathrm{kg}^{-1}\right)$ was found to be normal in all 16 study patients. The protocol of electrophysiological evaluation has been previously described $[7,8,10]$. Briefly, electrophysiological testing included the function of sinus and AV nodes and the His-Purkinje system. All study patients fulfilled the following criteria: sinus node recovery time $<1,500 \mathrm{~ms}$; increase in sinus rate of $>25 \%$ from baseline sinus rate to $>90 \mathrm{bpm}$ after administration of atropine; and an AV Wenckebach period $<505 \mathrm{~ms}$; and an $\mathrm{HV}$ interval $<55 \mathrm{~ms}$.

\section{Cardiorespiratory polysomnography}

All 16 patients underwent cardiorespiratory polysomnography. The following parameters were continuously recorded from approximately 22:00-06:00 h: 1) abdominal and thoracic respiratory excursions by inductive plethysmography (Respitrace; Studley Data System, Oxford, UK); 2) oronasal airflow (thermocouple airflow sensor; Pro-Tech Services, Woodinville, USA); 3) breathing sounds (laryngeal microphone; MAP, Martinsried, Germany); 4) pulse oximetry (N 100; Nellcor, Idstein, Germany); 5) 1 channel ECG (Polysomnographischer Messplatz; Schwarzer, München, Germany); 6) C3-A2 and C2-02 lead electroencephalogram (EEG) (Polysomnographischer Messplatz); 7) two-lead electro-oculogram (EOG) (Polysomnographischer Messplatz); and 8) two-lead electromyogram (EMG) (Polysomnographischer Messplatz). Simultaneously, a twochannel Holter ECG (Oxford Medilog 4,000; Oxford Instruments, Abingdon, UK) was recorded for $24 \mathrm{~h}$. Using this approach the cardiorespiratory parameters could exactly be defined at the time of each bradyarrhythmia detected by Holter ECG.

\section{Analysis of polysomnography and simultaneously Holter ECG}

Sleep stages were scored in $30 \mathrm{~s}$ epochs according to the criteria by ReChtschafFen and Kales [11]. An apnoea was defined as the cessation or reduction of $<20 \%$ of oronasal airflow with a minimum duration of $10 \mathrm{~s}$, hypopnoea as a reduction of oronasal airflow by at least $50 \%$ and a minimum duration of $10 \mathrm{~s}$, accompanied by a desaturation of at least $4 \%$. Heart block was analysed due to the pattern of ventilation (hypopnoea/apnoea), sleep stage (REM,NREM) and $\mathrm{Sa}_{\mathrm{a}} \mathrm{O}_{2}$. The value of $\mathrm{Sa}_{\mathrm{a}} \mathrm{O}_{2}$ before apnoea/hypopnoea associated arrhythmia, the minimum value during apnoea/ hypopnoea and $\Delta \mathrm{Sa}_{\mathrm{a}} \mathrm{O}_{2}$ (difference between $\mathrm{Sa}_{\mathrm{a}} \mathrm{O}_{2}$ before and at the end of apnoea/hypopnoea) were recorded.

The two-channel ECGs were printed out on paper in full length (one channel) with a paper speed of $4 \mathrm{~mm} \cdot \mathrm{s}^{-1}$. A two-channel printout of relevant periods was made at a paper speed of $25 \mathrm{~mm} \cdot \mathrm{s}^{-1}$. The arrhythmias analysed were: II $^{\circ}$ AV block type Mobitz; III $^{\circ}$ AV block; and sinus arrest. Up to three consecutive nonconducted $P$ waves were classified as $\mathrm{II}^{\circ} \mathrm{AV}$ block type Mobitz, four or more nonconducted consecutive $\mathrm{P}$ waves as $\mathrm{III}^{\circ} \mathrm{AV}$ block. An asystole of at least $2 \mathrm{~s}$ duration without evident $\mathrm{P}$ wave was classified as sinus arrest. 


\section{Statistical analysis}

Statistical comparison of data was performed using the Chi-squared test, Student's t-test and Wilcoxon's rank sum test where appropriate. All results are reported as mean \pm SD and range. Significance was assumed at a p-value $<0.05$.

\section{Results}

\section{Polysomnography and Holter ECG}

The results of polysomnography are summarized in table 1. Moderate to severe sleep apnoea was present in all patients. The mean AHI (number of apnoeas and hypopnoeas per hour of sleep) was 75.5 events $\cdot \mathrm{h}^{-1}$. A proportion of REM sleep, $20.6 \%$ of total sleep time (TST), is at the

Table 1. - Results of diagnostic polysomnography

\begin{tabular}{lcc}
\hline AI events $\cdot \mathrm{h}^{-1}$ & $50.8 \pm 42.5$ & $(0.8-152.0)$ \\
HI events $\mathrm{h}^{-1}$ & $23.6 \pm 24.9$ & $(0-86.0)$ \\
AHI events $\cdot \mathrm{h}^{-1}$ & $75.5 \pm 39.6$ & $(12.0-152.0)$ \\
TST min & $312 \pm 80.7$ & $(147.0-439.8)$ \\
NREM stages 1 and $2 \%$ & $73.2 \pm 10.7$ & $(50.4-86.6)$ \\
NREM stages 3 and 4 \% & $6.2 \pm 8.3$ & $(0.0-30.5)$ \\
REM \% & $20.6 \pm 6.9$ & $(12.9-39.1)$ \\
\hline
\end{tabular}

Values are presented as mean \pm SD with range in parenthesis. AI: apnoea index; HI: hypopnoea index; AHI: apnoeic/hypopnoeic index; TST: total sleep time; NREM: nonrapid eye movement; REM: rapid eye movement. lower limit of the normal range. The proportion of NREM sleep stages III and IV of $6.2 \%$ was decreased.

Six hundred and fifty one nocturnal bradyarrhythmias were recorded: 178 episodes of sinus arrest, 432 episodes of $\mathrm{II}^{\circ} \mathrm{AV}$ block type Mobitz; and 41 episodes of $\mathrm{III}^{\circ} \mathrm{AV}$ block. During daytime no heart block was present in the Holter ECG. Mean, maximum and minimum values of duration of arrhythmias are listed in table 2. During apnoeas and hypopnoeas, 609 episodes of heart block occurred accompanied by a desaturation of at least $4 \%, 42$ with apnoeas and a desaturation of $<4 \%$.

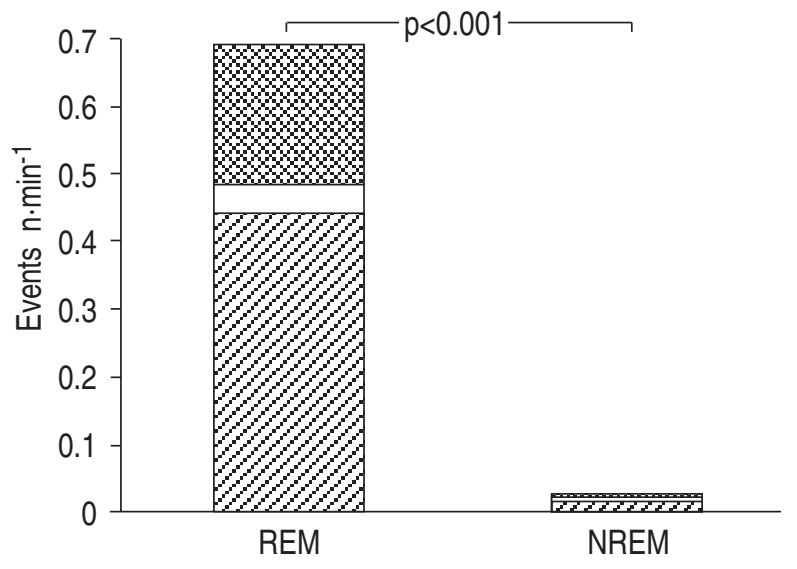

Fig. 1. - Distribution of episodes of apnoea-associated bradyarrhythmias due to rapid eye movement (REM) sleep and nonrapid eye movement (NREM) sleep stage. $Q: \mathrm{II}^{\circ}$ atrioventricular (AV) block; $\square: \mathrm{III}^{\circ}$ AV block; $\mathbb{\text { : }}$ : sinus arrest.

Table 2. - Duration of different bradyarrhythmias and the values of arterial oxygen saturation $\left(\mathrm{Sa}_{2}, \mathrm{O}_{2}\right)$ before/during apnoea/hypopnoea-associated arrhythmia

\begin{tabular}{lrrrrrl}
\hline & $\mathrm{n}$ & \multicolumn{2}{c}{ Duration } & $S_{\mathrm{a}, \mathrm{O}_{2}, \max } \%$ & \multicolumn{1}{c}{$\mathrm{S}_{\mathrm{a}, \mathrm{O}_{2}, \min } \%$} & $\Delta S_{\mathrm{a}, \mathrm{O}_{2}} \%$ \\
\hline II $^{\circ}$ AV block type Mobitz & 432 & $2.2 \pm 0.3$ & $(3.9)$ & $84.3 \pm 12.8$ & $66.6 \pm 17.5$ & $17.7 \pm 9.9$ \\
III $^{\circ}$ AV block & 41 & $7.0 \pm 3.9$ & $(18.5)$ & $83.7 \pm 14.8$ & $64.2 \pm 20.1$ & $19.5 \pm 15.0$ \\
Sinus arrest & 178 & $3.0 \pm 1.3$ & $(12.0)$ & $81.3 \pm 12.3$ & $64.2 \pm 13.5$ & $17.1 \pm 7.5$ \\
\hline
\end{tabular}

Values are presented as mean \pm SD with maximum value in parenthesis. $\mathrm{S}_{\mathrm{a}, \mathrm{O}_{2}}$, max : maximum arterial oxygen saturation; $\mathrm{Sa}_{\mathrm{a}} \mathrm{O}_{2}, \mathrm{~min}$ : minimum arterial oxygen saturation; $\Delta \mathrm{Sa}_{\mathrm{a}, \mathrm{O}_{2}}$ : the difference between the value of $\mathrm{Sa}_{\mathrm{a}} \mathrm{O}_{2}$ before and at the end of apnoea/hypopnoea: AV: atrioventricular.

Table 3. - Respiratory disturbance index (RDI), body mass index (BMI) and the distribution of bradyarrhythmias due to nonrapid eye movement (NREM) and rapid eye movement (REM) sleep for individual patients

\begin{tabular}{|c|c|c|c|c|c|c|c|c|c|c|c|c|c|c|}
\hline \multirow{2}{*}{$\begin{array}{l}\text { Patient } \\
\text { No }\end{array}$} & \multirow{2}{*}{$\begin{array}{c}\text { RDI } \\
\text { episodes } \cdot h^{-1}\end{array}$} & \multirow{2}{*}{$\begin{array}{c}\mathrm{BMI} \\
\mathrm{kg} \cdot \mathrm{m}^{-2}\end{array}$} & \multicolumn{3}{|c|}{ Sinus arrest } & \multicolumn{3}{|c|}{$\mathrm{II}^{\circ} \mathrm{AV}$ block } & \multicolumn{3}{|c|}{ III $^{\circ}$ AV block } & \multicolumn{3}{|c|}{ Sum } \\
\hline & & & Sum & NREM \% & REM \% & Sum & NREM \% & REM \% & Sum & NREM \% & REM \% & Sum & NREM \% & REM \% \\
\hline 1 & 53 & 29.4 & 0 & 0 & 0 & 193 & 2 & 98 & 11 & 0 & 100 & 204 & 1 & 99 \\
\hline 2 & 152 & 48.4 & 15 & 13 & 87 & 9 & 22 & 78 & 10 & 0 & 100 & 34 & 12 & 88 \\
\hline 3 & 15 & 54.2 & 41 & 0 & 100 & 0 & 0 & 0 & 0 & 0 & 0 & 41 & 0 & 100 \\
\hline 4 & 67 & 41.4 & 5 & 0 & 100 & 34 & 3 & 97 & 0 & 0 & 0 & 39 & 3 & 97 \\
\hline 5 & 32 & 32.8 & 0 & 0 & 0 & 28 & 0 & 100 & 2 & 0 & 100 & 30 & 0 & 100 \\
\hline 6 & 98 & 32.4 & 0 & 0 & 0 & 86 & 30 & 70 & 1 & 0 & 100 & 87 & 30 & 70 \\
\hline 7 & 45 & 33.0 & 1 & 0 & 100 & 0 & 0 & 0 & 0 & 0 & 0 & 1 & 0 & 100 \\
\hline 8 & 84 & 32.9 & 0 & 0 & 0 & 53 & 42 & 58 & 15 & 40 & 60 & 68 & 41 & 59 \\
\hline 9 & 118 & 45.7 & 97 & 11 & 89 & 0 & 0 & 0 & 0 & 0 & 0 & 97 & 11 & 89 \\
\hline 10 & 120 & 46.7 & 3 & 0 & 100 & 0 & 0 & 0 & 0 & 0 & 0 & 3 & 0 & 100 \\
\hline 11 & 75 & 34.1 & 4 & 0 & 100 & 0 & 0 & 0 & 0 & 0 & 0 & 4 & 0 & 100 \\
\hline 12 & 50 & 32.1 & 0 & 0 & 0 & 9 & 0 & 100 & 0 & 0 & 0 & 9 & 0 & 100 \\
\hline 13 & 102 & 34.0 & 6 & 17 & 83 & 0 & 0 & 0 & 1 & 0 & 100 & 7 & 14 & 86 \\
\hline 14 & 12 & 28.1 & 0 & 0 & 0 & 11 & 0 & 100 & 1 & 0 & 100 & 12 & 0 & 100 \\
\hline 15 & 104 & 29.4 & 6 & 0 & 100 & 0 & 0 & 0 & 0 & 0 & 0 & 6 & 0 & 100 \\
\hline 16 & 82 & 33.5 & 0 & 0 & 0 & 9 & 0 & 100 & 0 & 0 & 0 & 9 & 0 & 100 \\
\hline Total & & & 178 & & & 432 & & & 41 & & & 651 & & \\
\hline
\end{tabular}

$\mathrm{AV}$ : atrioventricular. 


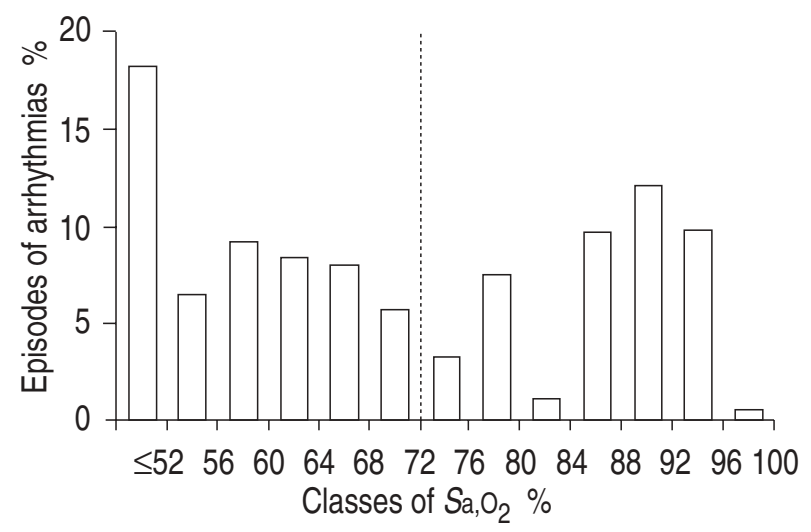

Fig. 2. - Distribution of frequencies of nocturnal bradyarrythmias (percentage of all episodes of arrhythmias) in different classes of arterial oxygen saturation $\left(\mathrm{Sa}_{\mathrm{a}} \mathrm{O}_{2}\right)$ (minimal values at end of apnoea). ....... threshold $\mathrm{S}_{\mathrm{a}, \mathrm{O}_{2}}$ value.
During REM sleep, 572 (87.9\%) episodes of sinus arrest and AV block occurred 79 (12.1\%) during NREM sleep stages 1 and 2 and none during NREM sleep stages 3 and 4. During REM sleep, the frequency of bradyarrhythmias was significantly higher than during NREM sleep (fig. 1): $0.69 \pm 0.99$ versus $0.02 \pm 0.04$ episodes of arrhythmias $\cdot \mathrm{min}^{-1}$ of the respective sleep stage $(\mathrm{p}<0.001)$. Table 3 demonstrates the distribution of bradyarrhythmias due to sleep stages (NREM/REM) for individual patients.

Of all bradyarrhythmias, $56.1 \%$ were found below the critical $\mathrm{Sa}_{\mathrm{a}} \mathrm{O}_{2}$ value of $72 \% ; 87.1 \%$ of sinus arrest, $58.5 \%$ of $\mathrm{III}^{\circ} \mathrm{AV}$ block and $43.1 \%$ of $\mathrm{II}^{\circ} \mathrm{AV}$ block. Figure 2 demonstrates arrhythmias in relation to different classes of oxy-gen desaturation. There were no differences between the values of $\mathrm{Sa}_{\mathrm{a}} \mathrm{O}_{2}$ at the beginning and at the end of apnoea concerning the different types of bradyarrhythmias (table 2). Figures $3 \mathrm{a}$ and $\mathrm{b}$ show parts of the polysomnographic recordings in two patients with $\mathrm{III}^{\circ} \mathrm{AV}$

a)

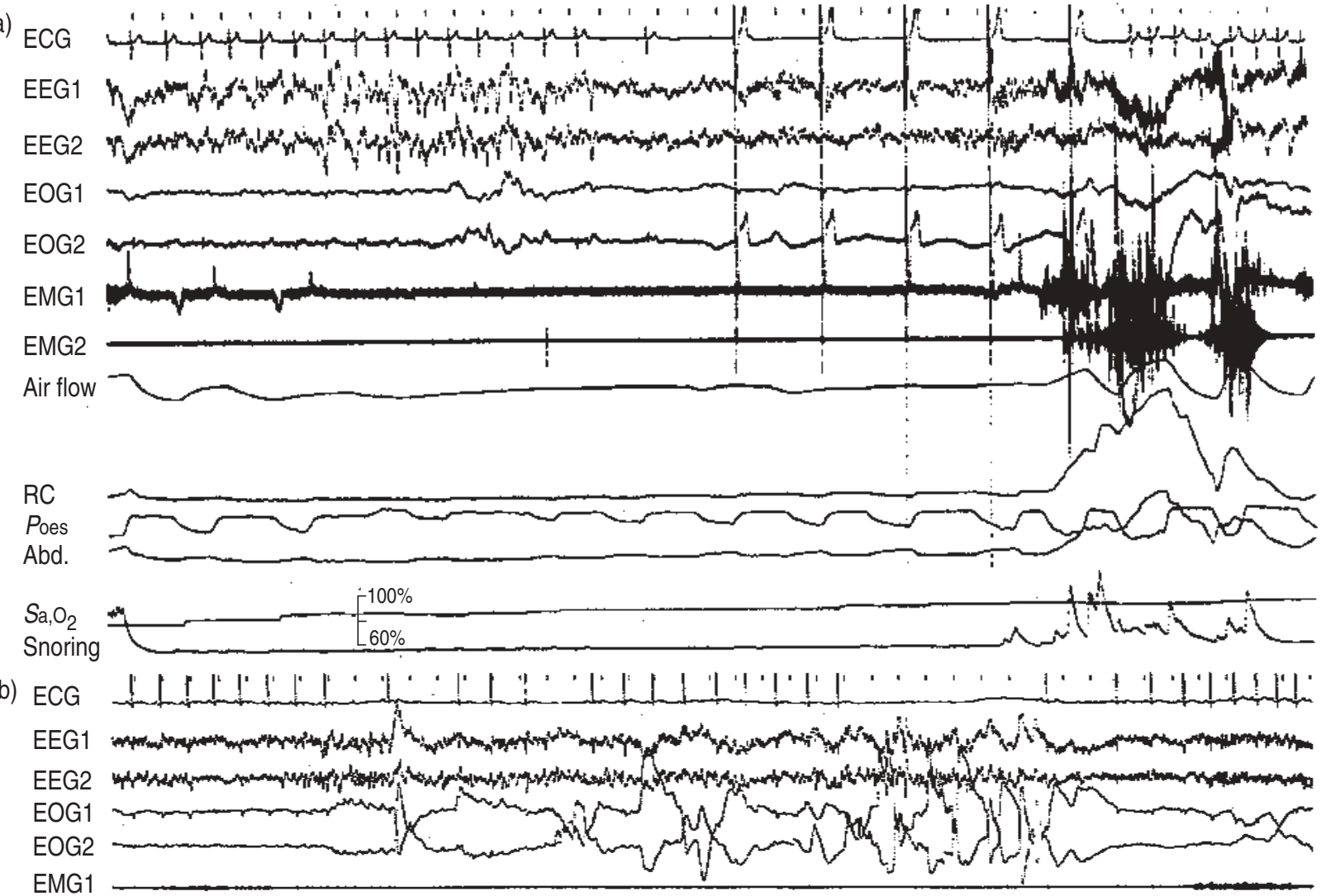

EMG2

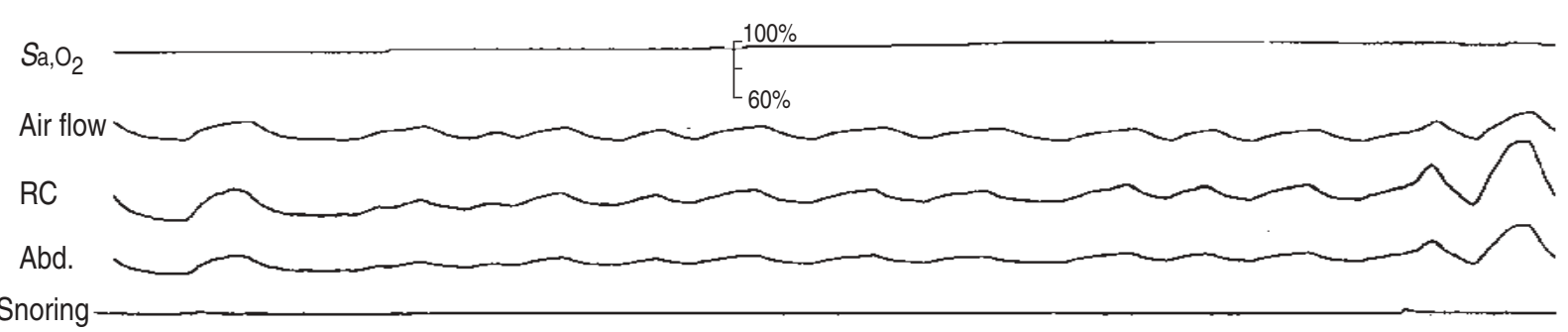

$10 \mathrm{~s}$

Fig. 3. - Part of a polysomnographic recording in two patients with $\mathrm{III}^{\circ} \mathrm{AV}$ block. a) Cardiac pacemaker was implanted in one patient because of the extreme duration of heart block (up to $18.5 \mathrm{~s}$ ). During an apnoea, five pacemaker-induced ventricular contractions can be seen. b) III ${ }^{\circ} \mathrm{AV}$ block occurring during a hypopnoea with only minimal desaturation during rapid eye movement sleep. ECG: electrocardiogram; EEG: electroencephalogram; EOG: electro-oculogram; EMG: electromyogram; RC: ribcage; $P$ oes: oesophageal pressure; Abd.: abdominal; $\mathrm{Sa}_{\mathrm{a}} \mathrm{O}_{2}$ : arterial oxygen saturation. 
block. Note that heart block is occurring during hypopnoea with only mild desaturation during REM sleep (3b).

\section{nCPAP/nBiPAP therapy}

With nCPAP/nBiPAP therapy, obstructive sleep apnoea could be treated effectively. The AHI was reduced from $75.5 \pm 39.6$ to $3.0 \pm 6.6$ events $\cdot h^{-1}(\mathrm{p}<0.01)$. nCPAP/nBiPAP completely eliminated bradyarrhythmias in nine patients, clearly reduced the frequency of AV blocks and sinus arrests in five patients and produced no relevant alterations in two patients. With regard to the total number of arrhythmias, the frequency could be reduced from 651 to 72 episodes $(p<0.01)$. Permanent cardiac pacemaker implantation was carried out in four patients who had still experienced long-lasting asystoles $>5 \mathrm{~s}$, despite effective therapy $(n=3)$, or who were noncompliant $(n=1)$. Concerning diagnoses, there were no relevant differences between the patients with an increase/decrease of bradyarrhythmias with nCPAP/nBiPAP therapy. The AHI in the two patients with increased frequency of heart block were 50 events $\cdot \mathrm{h}^{-1}$ and 102 events.h-1 ${ }^{-1}$. Neither patient had chronic obstructive lung disease; arterial oxygen tension $\left(\mathrm{Pa}, \mathrm{O}_{2}\right)$ values at rest were 10.44 and $9.92 \mathrm{kPa}(78.5$ and $74.6 \mathrm{mmHg})$.

\section{Discussion}

This study describes the relationship between nocturnal bradyarrhythmias and sleep stage in patients with sleep apnoea and normal electrophysiological evaluation of sinus node function and AV conduction system. The major finding of the present study is that apnoea-associated bradyarrhythmias show a clear predominance during REM sleep. In contrast to previous reports, we did not find a $\mathrm{Sa}_{\mathrm{a}} \mathrm{O}_{2}$ threshold value for the occurrence of heart block. In addition, our data confirm the effectiveness of nCPAP/nBiPAP in the reversal of arrhythmias in patients with obstructive sleep apnoea.

Nocturnal bradyarrhythmias in patients with obstructive sleep apnoea have been described by numerous authors [1-5], but there are few data on the influence of sleep stage on nocturnal bradyarrhythmias in normals and in patients with sleep apnoea. Gulleminault et al. [12] reported asystolic periods up to $9 \mathrm{~s}$ in duration only during REM sleep in four apparently healthy young adults without sleep-related breathing disorder. Nevins [13] describ-ed the case of a patient with heart failure who developed episodes of AV block also during REM sleep. OTsuKa et al. [14] reported an increase of frequency of $\mathrm{I}^{\circ}$ and $\mathrm{II}^{\circ} \mathrm{AV}$ block in REM sleep and an increase of $\mathrm{III}^{\circ} \mathrm{AV}$ block in NREM sleep. The incidence of profound bradyarrhythmias during REM sleep is unknown, some studies have shown that asystoles lasting longer than $2.5 \mathrm{~s}$ are rare in healthy subjects [15-19]. Guilleminault et al. [2] report-ed the occurrence of heart block in patients with obstructive sleep apnoea only during NREM sleep stage 2 and REM sleep, but there are no data about frequency.

In humans, $f \mathrm{C}$ is lower in NREM and REM sleep when compared to wakefulness. There are conflicting data concerning mean $f C$ in NREM and REM sleep. REM sleep is characterized by a high variability of $f C$ with lowest and highest $f c$ values, which may be due to differences between tonic and phasic REM [20].
Although apnoea duration and oxygen desaturation are more pronounced during REM sleep, the degree of oxygen desaturation does not seem to play the major role in the pathogenesis of heart block. Therefore, it would be interesting to know if oxygen application leads to a reduction or an elimination of apnoea-associated arrhythmias. It is possible that REM sleep per se, which normally shows a desynchronization of respiration and cardiovascular function, leads to excessive autonomic response due to stronger stimulation of chemo- and baroreceptors induced by hypoxaemia, intrathoracic pressure swings and haemodynamic alterations. SOMERs et al. [21] proposed baroreflex impairment (mainly found in patients with arterial hypertension and heart failure) results in uninhibited and excessive chemoreflex-mediated parasympathetic and sympathetic discharge in patients with sleep apnoea.

Changes in heart rhythm are a typical finding in patients with sleep apnoea. The characteristic pattern is the so called cyclical variation of $f \mathrm{C}$ with slowing during apnoea and acceleration during the post apnoeic hyperventilation. Bradyarrhythmias are found in about $5-10 \%$ of patients with obstructive sleep apnoea [1-5]. Compared to healthy subjects of similar age, heart block events during sleep are much more frequent and their duration markedly longer [17-19]. Due to ventricular asystolies of up to $15 \mathrm{~s}$ in duration, it was thought that heart block might lead to an increased mortality risk in this patient group.

As the i.v. application of atropine eliminates cyclical variation of $f \mathrm{C}$ and bradyarrhythmias an increased vagal tone has been postulated as the cause of apnoea-associated arrhythmia [22]. Coronary heart disease is a rare finding in patients with sleep-related heart block and does not play an important role in the pathogenesis [6].

We cannot confirm the finding by Gulleminault et al. [2] that nocturnal bradyarrhythmias in patients with sleep apnoea exclusively occur below a $\mathrm{Sa}_{\mathrm{a}} \mathrm{O}_{2}$ threshold value of $72 \%$. In the present study only $56.1 \%$ of heart blocks were found below this threshold value. It is interesting to note that some patients develop heart block in REM sleep without any or with only mild desaturation.

ZwLLich et al. [23] reported that hypoxaemia and cessation of respiration are essential in the development of bradycardia in patients with apnoea. The degree of bradycardia is closely related to the severity of hypoxaemia, but not correlated with sleep stage or type of apnoea. When hypoxia during apnoea is prevented by oxygen breathing, bradycardia during apnoea does not occur or is markedly reduced. In patients with sleep apnoea and heart block no data exist about the influence of oxygen application, probably because of the fact that oxygen might induce prolongations of apnoea and heart block duration.

The cardiovascular and pulmonary system serve the goal of delivering oxygen to tissues. Normal responses to hypoxia and hypercapnia are an increase in $f \mathrm{C}$ and ventilation. The mechanisms mediating the tachycardic response to hypoxaemia are not clearly understood. Studies in animals with artificial ventilation and lung denervation on the interaction of $f \mathrm{C}$ and ventilation demonstrated that hypoxic stimulation of carotid chemoreceptors alone induces a progressive bradycardia. Lung inflation via pulmonary stretch receptors seems to play a key role in modifying parasympathetic response, resulting in $f C$ acceleration with hypoxia. So the primary response to hypoxia is bradycardia, which only becomes apparent during apnoea, when the 
influence of hyperventilation mediated by pulmonary stretch receptors is eliminated [24-27].

A point of further interest is the manifestation and the degree of pharyngeal obstruction, because it is also known that an excitation of pharyngeal mechanoreceptors due to airway obstruction can induce bradycardia. Besides severe obstructive sleep apnoea and REM sleep obesity seems to be another factor contributing to the occurrence of heart block. One can imagine that the degree of pharyngeal obstruction is much more pronounced in patients who are overweight. So it is possible that the more the pharyngeal airway is obstructed the more vagal activation by mechanoreceptors is necessary to open the closed airway.

$f C$ changes depend on the balance of both sympathetic and parasympathetic tone. In patients with obstructive sleep apnoea nocturnal bradyarrhythmias are undoubtedly due to heightened parasympathetic tone. The mechanisms affecting the imbalance of sympathetic/parasympathetic tone in these patients are not clearly understood, but REM sleep may be one of the major pathogenetic factors contributing to powerful vagal stimulation inducing nocturnal heart block.

Our therapeutic strategy is not to implant a cardiac pacemaker if heart block can be successfully eliminated by nasal continuous positive airway pressure/nasal bilevel positive airway pressure and if the patient shows satisfactory compliance with therapy. In cases of long-lasting asystoles (>5 s), an electrophysiological evaluation seems sensible in order not to miss possible structural damage of sinus node function and conduction system. The prognostic significance of prolonged asystolic episodes in patients with obstructive apnoea still remains unclear. Although an increased mortality and sudden deaths have been reported in patients with severe sleep apnoea, a cause-effect relationship to heart block has not yet been established.

\section{References}

1. Flemons WW, Remmers JE, Gillis AM. Sleep apnea and cardiac arrhythmias. Is there a relationship? Am Rev Respir Dis 1993; 148: 618-621.

2. Guilleminault C, Connolly SJ, Winkle RA. Cardiac arrhythmia and conduction disturbances during sleep in 400 patients with sleep apnea syndrome. Am J Cardiol 1983; 52: 490-494.

3. Koehler U, Fett I, Hay J, et al. Bradycarde Herzrhythmusstörungen im Schlaf - Morbiditatsspektrum bei Patienten mit Schlaf-Apnoe und nachtlichen bradycarden Herzrhythmusstorungen. In: Peter JH, Cassel W, Penzel T, eds. Schlaf-Atmung-Kreislauf. Berlin, New York, Springer 1993: pp. 374-383.

4. Miller WP. Cardiac arrhythmias and conduction disturbances in the sleep apnea syndrome. Prevalence and significance. Am J Med 1982; 73: 317-321.

5. Becker $\mathrm{H}$, Brandenburg U, Peter JH, vonWichert $\mathrm{P}$. Reversal of sinus arrest and atrioventricular conduction block in patients with sleep apnea during nasal continuous positive airway pressure. Am J Respir Crit Care Med 1995; 151: 215-218.

6. Koehler U, Wetzig T, Peter JH, Ploch T, Schafer H, Stellwaag M. Morbiditat und Letalitat bei Schlafapnoe und nachtlichen Bradyarrhythmien. Dtsch Med Wochenschr 1994; 119: 1187-1193.

7. Grimm W, Hoffmann J, Koehler U, et al. Invasive electrophysiological evaluation of patients with sleep apnea- associated ventricular asystole - methods and preliminary results. J Sleep Res 1995; 4: 160-165.

8. Grimm W, Hoffmann J, Menz V, et al. Electrophysiologic evaluation of sinus node function and atrioventricular conduction in patients with prolonged ventricular asystole during obstructive sleep apnea. Am J Cardiol 1996; 77: 1310-1314.

9. Casale PN, Devereux RB, Milner M, et al. Value of echocardiographic measurement of left ventricular mass in predicting cardiovascular morbid events in hypertensive men. Ann Intern Med 1986, 105: pp. 173-178.

10. Josephson ME. Clinical Cardiac Electrophysiology Techniques and Interpretations. 2nd Edn. Philadelphia/ London, Lea and Febiger, 1993.

11. Rechtschaffen A, Kales A. A manual of standardized terminology: techniques and scoring system for sleep stages of human subjects. Los Angeles, UCLA Brain Information Service/Brain Research Institute, 1968.

12. Guilleminault C, Pool P, Motta J, Gillis AM. Sinus arrest during REM sleep in young adults. N Engl J Med 1984; 311: 1006-1010.

13. Nevins DB. First and second-degree A-V heart block with rapid eye movement sleep. Ann Intern Med 1972; 76: 981-983.

14. Otsuka K, Ichimaru Y, Yanaga T, Sato Y. Studies of arrhythmias by 24-hour polygraphic recordings: relationship between atrioventricular block and sleep states. Am Heart J 1983; 105: 934-940.

15. Brodsky M, Delon WU, Denes P, Kanakis C, Rosen KM. Arrhythmias documented by 24 hours continuous electrocardiographic monitoring in 50 male medical students without apparent heart disease. Am J Cardiol 1977; 39: 390-395.

16. Sobotka PA, Mayer JH, Bauernfeind RA, Kanakis C, Rosen KM. Arrhythmias documented by 24-hour continuous ambulatory electrocardiographic monitoring in young women without apparent heart disease. Am Heart J 1981; 101: 753-759.

17. von Leitner ER, Andresen D, Reinhardt M, Tietze U, Schröder R. Langzeit-EKG-Untersuchungen von herzgesunden Normalpersonen mit rechnercompatiblem Analysesystem. Intensivmed 1979; 16: 184-188.

18. Bjerregaard P. Mean 24 hour heart rate, minimal heart rate and pauses in healthy subjects $40-79$ years of age. Eur Heart J 1983; 4: 44-51.

19. Clarke JM, Hamer J, Shelton JR, Taylor S, Venning GR. The rhythm of the normal human heart. Lancet 1976; 508-512.

20. George CF, Kryger MH. Sleep and control of heart rate. Clin Chest Med 1985; 6: 595-601.

21. Somers VK, Dyken ME, Mark AL, Abboud FM. Parasympathetic hyperresponsiveness and bradyarrhythmias during apnoea in hypertension. Clin Auton Res 1992; 2: 171-176.

22. Koehler U, Funck R, Fus E, et al. Bradykarde Arrhythmien bei schlafbezogenen Atmungsstorungen. Klinische Relevanz, Pathogenese und Therapie. Dtsch Med Wochenschr 1995; 120: 1369-1373.

23. Zwillich C, Devlin T, White D, Douglas N, Weil J, Martin R. Bradycardia during sleep apnea. Characteristics and mechanism. J Clin Invest 1982; 69: 1286-1292.

24. Simon PM, Taha BH, Dempsey JA, Skatrud JB, Iber C. Role of vagal feedback from the lung in hypoxic-induced tachycardia in humans. J Appl Physiol 1995; 78: 1522-1530.

25. Daly M, de B. The cardiovascular responses to stimulation of the carotid body chemoreceptors in the dog. $J$ Physiol (Lond) 1963; 165: 179-197.

26. Kato H, Menon AS, Chen FJ, Slutsky AS. Contribution of pulmonary receptors to the heart rate response to acute hypoxemia in rabbits. Circ 1988; 78: 1260-1266.

27. Kato H, Menon AS, Slutsky AS. Mechanisms mediating the heart rate response to hypoxemia. Circ 1988; 77: 407-414. 